\title{
Study of effects Oat and Soybean on the Microbial and Sensory Analysis of Burgers (Beef, Chicken and Sheep)
}

${ }^{1}$ Food science department, college of Agriculture, Tikrit University, Tikrit, Iraq

${ }^{2}$ Department of Biotechnology, College of Applied Science, University of Fallujah, Ministry of Higher Education and Scientific Research, Republic of Iraq.

${ }^{3}$ Food Science department, College of Agriculture, University of Anbar, Al-Anbar, Iraq.

Corresponding author: firasraidth1983@gmail.com

Abstract: The purpose of this study was to assess the microbiological and sensory load induced by fast-food energy reduction as an adjuvant treatment for autism, obesity, and the preparation of low-fat burgers and assess the effect of soybean and oat flour as fat substitutes. There were three treatments of the burgers consisting of (beef, chicken and sheep) for both oat and soybean and the ratio of 5,10 and $15 \%$ of each one as fundamental material used for manufacturing the model products. The burger that consists of types of meat with fillers of oats $10 \%$ and soy $10 \%$ then $5 \%$ and $15 \%$ respectively improves microbial load and sensory score. The burger that consists of types of meat with fillers of oats and soy in several concentrations Improves microbial load and sensory score.

Key words: Types of meat, Sensory analysis, Burgers, Microbial, Oats, Soybean.

\section{Introduction}

In today's trend, consumers' perceptions of food intake are mostly focused on keeping good health¹. Reduced fat in the diet, balanced protein sources, and, most crucially, the inclusion of recommended levels of dietary fiber sources in the daily diet have all grown more popular ${ }^{1}$. The burger was first served to the United States through fast-food establishments. Burgers, sausages, hotdogs, and nuggets, among other meat items, are widely accepted and consumed in Iraq, particularly in fast-food outlets.

Recent research has focused chiefly on the development of new alternatives that, when introduced into meat products, would allow for the production of low-energy goods with an enriched content of useful components not found in meat raw material ${ }^{2}$. Cereal grains, such as buckwheat and oats, have been used as alternatives for low-fat meat products ${ }^{2}$. Cereal grains, such as oats and buckwheat, are high in various nutrients that are in good proportions for an organism². Furthermore, it is a primary source of important components with a wide spectrum of biological activity (for example, polyphenols), whose consumption protects against the development of civilization diseases ${ }^{3}$.

In the low-fat meat system, the combination of isolated soy protein, alginate, and carrageenan can give emulation stability and restrict water development, which is based on stable complex formation and deformation of meat protein during the heating process ${ }^{4}$. The primary goal of separated soy protein is to enhance thickness, prevent water loss, and stabilize emulsion while lowering production costs.

There was a link between home hamburger preparation and the risk of contamination. A potential mechanism by which soy protein induces lowering of blood cholesterol concentrations includes thyroid status, bile acid balance and the estro- genic effects of genistein and daidzein ${ }^{5}$.

The objectives of the present experiment were to evaluate the effects of adding with different proportions of oat or soya (5,10, and $15 \%)$ mixed with (Ground meat) of (cow, chicken and sheep) in fast-food on quality burgers (sensory evaluation and microbiological load).

\section{Materials and methods}

Comminuted products of the following general composition made up the material: Burgers were made with various proportions of oat or soya $(5,10$, and $15 \%)$ mixed with minced meat products (beef, chicken, and sheep) at a rate of $75 \mathrm{~g}$ in the manufacturing of burgers. $20 \mathrm{~g}$ fat, $5 \mathrm{~g}$ samoon powder (a type of famous bread in (raq), $1.5 \mathrm{~g}$ sodium chloride, and $0.5 \mathrm{~g}$ spices; the spices are made up of a proportion of (black pepper, Kebabah, Nutmeg, Cloves and CINNAMON).

In a grinder, meat and delicate fat were minced. The amounts of oat or soya (5,10, and $15 \%)$ were mixed with minced meat products (beef, chicken, and sheep) at a rate of $75 \mathrm{~g}$ and stored for 24 hours under refrigeration ( $4 \pm 10 \mathrm{C}$ ).

\section{The Burger Processing Instructions}

The ingredients are added to the mixture mixed for another 4 minutes. The temperature of the combination was monitored regularly to ensure that it remained between 10 and 15 degrees Celsius. The flavors and spices are then combined.

This was when the finely powdered soybean or oat was added to the mixture for samples T 1, T 2, and T3. The mixture was then beaten for a further 2 minutes. After that, each burger is weighed at 75 grams. After being molded and kept cold

Citation: Mohammed Saleh H, Jameel FR, Thamer Hadi S, Majed Hamid M. Study of effects Oat and Soybean on the Microbial and Sensory Analysis of Burgers (Beef, Chicken and Sheep).Revis Bionatura 2022;7(1). 23. http://dx.doi.org/10.21931/RB/2022.07.01.23

Received: 7 November 2021 / Accepted: 20 November 2021 / Published: 15 February 2022

Publisher's Note: Bionatura stays neutral with regard to jurisdictional claims in published maps and institutional affiliations. 


\begin{tabular}{|l|l|l|}
\hline \multicolumn{1}{|c|}{ Ingredients } & \multicolumn{1}{|c|}{$\begin{array}{c}\text { Level of replacement } \\
(\mathbf{\%})\end{array}$} & $\begin{array}{l}\text { The filling Minced } \\
\text { meat products) }\end{array}$ \\
\hline Oat1 & $5 \%$ & Beef $75 \mathrm{~g}$ \\
Oat2 & $10 \%$ & Chicken $75 \mathrm{~g}$ \\
Oat3 & $15 \%$ & Sheep $75 \mathrm{~g}$ \\
Soya & $5 \%$ & \\
Soya & $10 \%$ & \\
Soya & $15 \%$ & \\
fat & $20 \mathrm{~g}$ & \\
Samoon powder & $5 \mathrm{~g}$ & \\
NaCl & 1.5 & \\
spices & $0.5 \mathrm{~g}$ & \\
\hline
\end{tabular}

Table 1. Describe the components of treatment types.

at a temperature of $-18^{\circ} \mathrm{C}$ for 1 to 2 hours, they are packed separately and kept cold for analysis purposes.

\section{Sensory evaluation}

Sensory evaluation: A well-trained group of 9 people with qualified sensory sensitivity evaluated the sensory quality of beef products, as specified by (6).

Texture, color, aroma, taste, flavor, and general acceptability were evaluated using a 7-point hedonic scale (7 like very much and 1 dislike very much). Technical staff members from the Departments of Meat Science and Technology and Poultry Science made up the sensory panel. Without any prior knowledge of the treatments, the panelists evaluated all of the features in each sample and marked the scales accordingly. The sensory evaluation sensory laboratory was used to simultaneously conduct the sensory evaluation using all of the panelists. The frozen nuggets were thawed in the refrigerator for 4 hours, then heated in a microwave oven before being served at room temperature on white porcelain plates in natural light to the panelists. The samples were assigned three-digit random numbers, and the presentation order was determined by random permutation. The sensory assessment was completed in the sensory laboratory. To ensure that each panelist made an independent decision, all required steps were taken?

\section{Coliform Counts}

After incubation at $37^{\circ} \mathrm{C}$ for 24 hours, Using a chromogenic E. coli/Coliform medium, Coliform Counts "TCC" (log CFU g1) were calculated (Rapid E. coli 2 Agar, Bio-Rad, Marnes La Coquette, France) $)^{8}$.

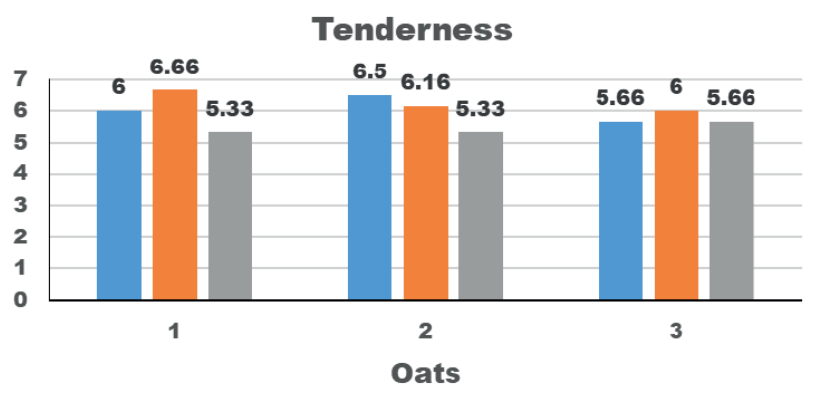

Beef Chicken $\square$ Sheep

Figure 1. Experimental treatments regarding tenderness with Oats.

\section{Statistical analysis}

Three biological replicates were used in each experiment. One-way ANOVA was used to examine the statistical differences between the treatment group's means (quantitative variables), followed by repeated pairwise comparisons (Tukey's test, 0.05). SPSS version 20.0 and GraphPad Prism were used for statistical analyses and graphics. The differences between the three biological replicates were considered significant at $p<0.05$, and the data were reported as mean SD.

\section{Results}

\section{Regarding sensory}

\section{Concerning tenderness}

The results for Oats illustrated there was no statistical significance at $p<0.01$ in all treatments, While the sub (Chicken) of T1 (Oats5\%) and the sub (Beef) of T3 (Oats15\%) recorded 5.66 for each one Numerically high recorded.

While regarding soya, the results illustrated there was statistical significance at $p<0.01$ between treatments, where all treatments recorded the highest significance statistically compared to the sub (Beef) of T1(Soya 5\%) and the sub (Chicken) of T1, T3(Soya 5,15\%) were recording (5.33), (5.66 and $5.00)$ respectively, which, in turn, showed a significant increase compared to the sub (Beef) of T3(Soya 15\%)was recording the treatment lowest significance at $(p<0.01)(4.66)$.

\section{Tenderness}

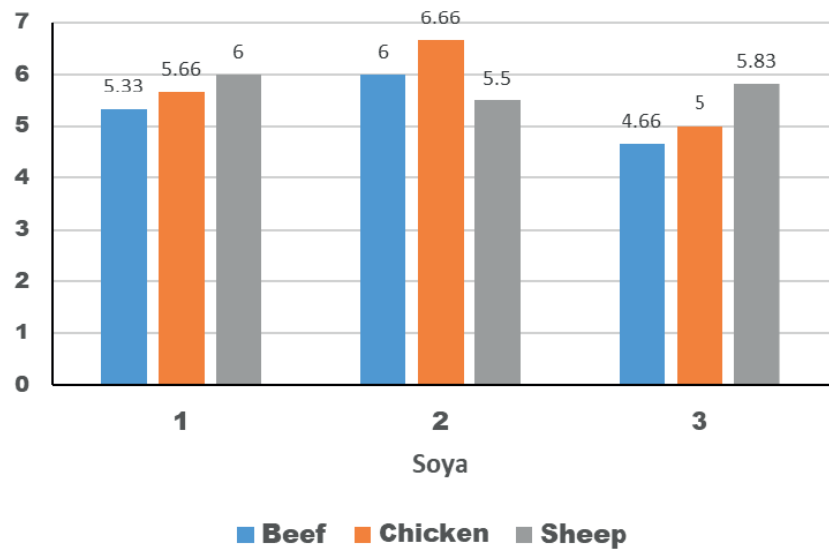

Figure 2. Experimental treatments regarding tenderness with soya. 


\section{Concerning color}

The results for Oats illustrated there was no statistical significance at $p<0.01$ between treatments, While the sub (Beef) of T2 (Oats10\%) recorded 6.83 for each one Numerically high recorded.

While regarding with soya, the results illustrated there were statistical significance at $p<0.01$ between treatments, where all treatments recorded statistical a highest significant compare to the sub (Beef) of T3 (Soya 15\%) were recording lowest significant at $(p<0.01)(4.66)$.

\section{Concerning Flavour}

The results for Oats, the results illustrated there was statistical significance at $p<0.01$ between treatments, where all treatments recorded the highest significance statistically compared to the sub (Beef) of T3 (Oats15\%) and the sub (sheep) of $\mathrm{T} 1$ of (Oats $5 \%$ ) were recording lowest significant at $(p<0.01)$ (5.83), (5.00) as respectively.

The results for soya results illustrated that there was statistical significance at $p<0.01$ between treatments, where all treatments recorded the highest effective compare statistically to the sub (Beef) of T3 (Soya 15\%) were recording lowest significance at $(p<0.01)(4.66)$.

\section{Concerning General acceptance}

The results for Oats results illustrated there were statistical significance at $p<0.01$ between treatments, where all treatments recorded a highest significant compare statistically to the sub (Beef) of T1 (Oats5\%) and the sub (Chicken) of

\section{Color}

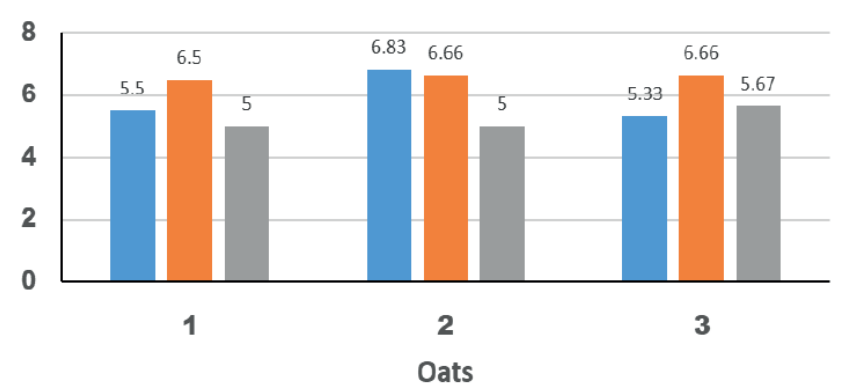

- Beef Chicken $\quad$ Sheep

Figure 3. Experimental treatments regarding color with Oats.
T3 (Oats15\%) were recording lowest significant at $(p<0.01)$ (5.33), (6.00) as respectively.

The results for soya results illustrated that there was statistical significance at $p<0.01$ between treatments, where all treatments recorded a highest effective compare statistically to the sub (Beef) of T3 (Soya 15\%) were recording lowest significance at $(p<0.01)(5.67)$.

\section{Concerning juiciness}

The results for Oats the results illustrated there was statistical significance at $p<0.01$ between treatments, where all treatments recorded the highest significance statistically compared to the sub (Chicken) of T3 (Oats15\%) were recording lowest significance at $(p<0.01)(5.66)$.

The results for soya results illustrated that there was statistical significance at $p<0.01$ between treatments, where all treatments recorded the highest significance statistically compared to the sub (Beef) of T3 (Soya15\%) were recording the lowest significance at $(p<0.01)(4.66)$.

\section{Regarding with microbiology aspect}

\section{Concerning Coliform}

The results for Oats the results illustrated there was statistical significance at $p<0.05$ between treatments, the sub (T3) at 15\% the sub of beef recorded best significance statistically (1.70) log CFU/g in terms of reduced microbial load compared to other treatments, especially (T3) at 15\% the sub of

\section{Color}

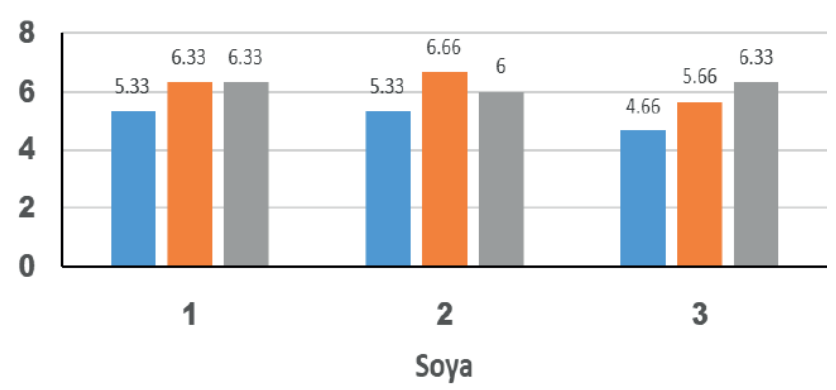

n Beef $n$ Chicken $n$ Sheep

Figure 4. Experimental treatments regarding color with soya.

\section{Flavor}

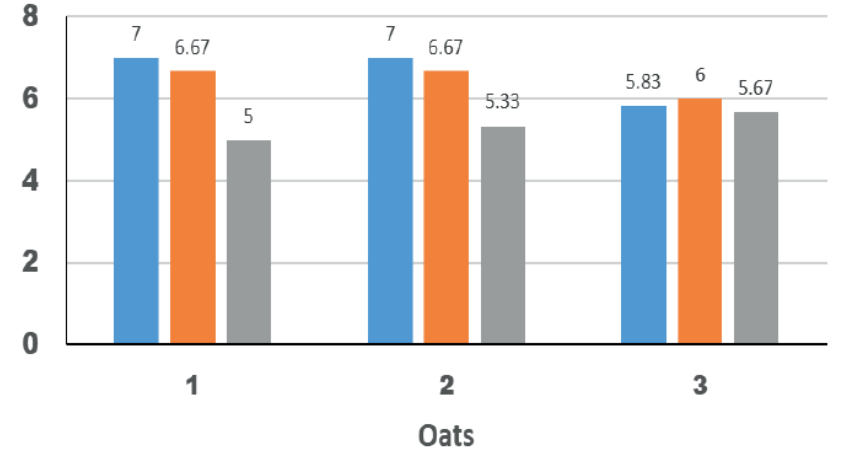

neef Chicken Sheep

Figure 5. Experimental treatments regarding Flavour with Oats. 
General acceptance

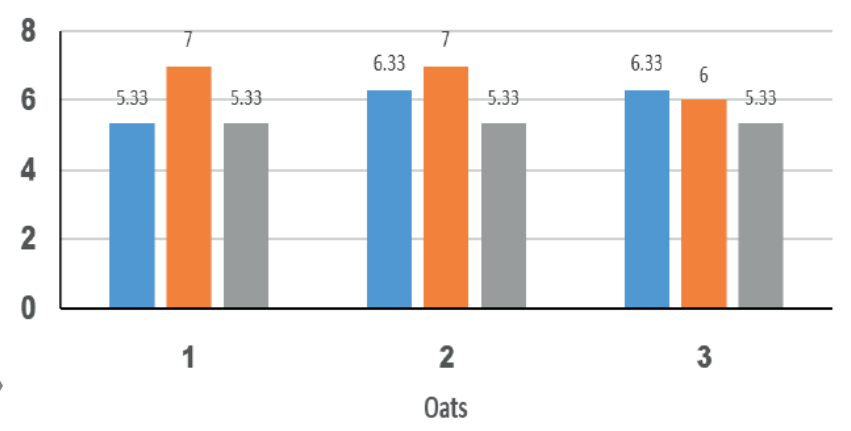

- Beef Chicken - Sheep

Figure 7. Experimental treatments regarding General acceptance with Oats.

Juiciness

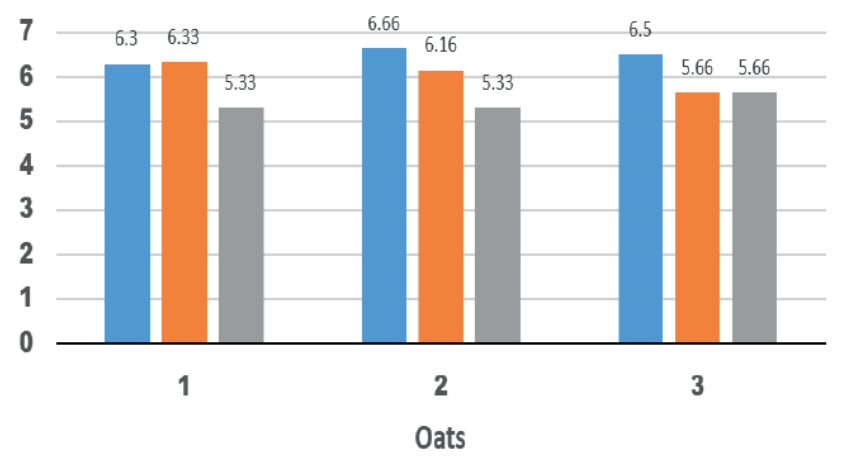

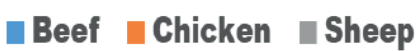

Figure 9. Experimental treatments regarding juiciness with Oats.

chicken that recorded lowest significance (95.6)log CFU/g in terms of rising microbial load.

The results for soya the results illustrated there was statistical significance at $p<0.05$ between treatments, the sub (T3) at 15\% the sub of beef recorded the lowest significance (1.3) log CFU/g in terms of rising microbial load compared to other treatments, especially Chicken and Sheep that recorded high significance (0.00) log CFU/g in terms of reducing microbial load.

\section{Concerning Yeast \& Mold}

The results for Oats the results illustrated there was statistical significance at $p<0.05$ between treatments, the sub $(\mathrm{T} 1, \mathrm{~T} 2)$ at $5 \%, 10 \%$ the sub of beef recorded lowest significance (1.0) $\log \mathrm{CFU} / \mathrm{g}$ in terms of rise microbial load compared to other treatment, especially Chicken and Sheep that recorded high significance $(0.00) \log \mathrm{CFU} / \mathrm{g}$ in terms of reducing microbial load.

The results for soya the results illustrated there was statistical significance at $p<0.05$ between treatments, the sub (T3) at 15\% the sub of beef recorded lowest significance (1.3) $\log \mathrm{CFU} / \mathrm{g}$ in terms of rise microbial load with an offer $(\mathrm{T} 1, \mathrm{~T} 2)$ at 5\%, 10\% recorded (1.0) log CFU/g compared to other treatment, especially Chicken and Sheep that recorded high significance (0.00) log CFU/g in terms of reducing microbial load.
General acceptance

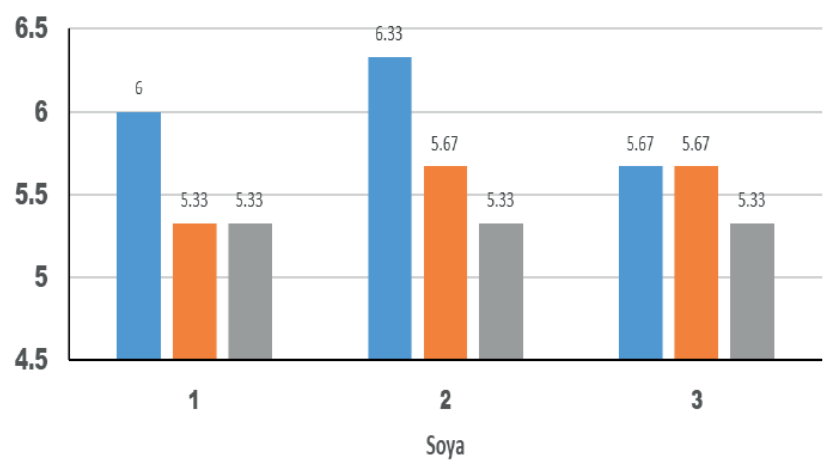

-Beef $\|$ Chicken $\|$ Sheep

Figure 8. Experimental treatments regarding General acceptance with Soya.

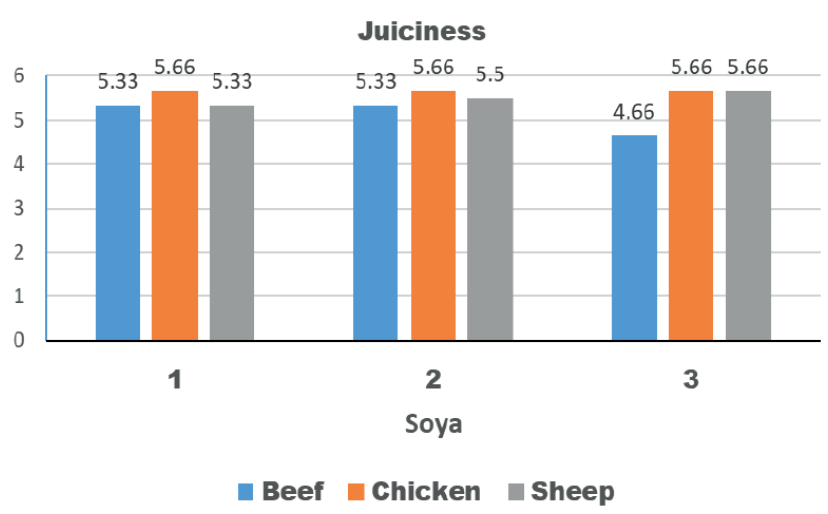

Figure 10. Experimental treatments regarding juiciness with Soya.

\section{Concerning Total Count Bacteria}

The results for Oats the results illustrated there was statistical significance at $\mathrm{p}<0.05$ between treatments, the sub (T3) at 15\% the sub of chicken recorded the lowest significance (2.96) log CFU/g in terms of rise microbial load compared to other treatments, especially the sub (T1) at 5\% the sub of beef that recorded high significance (2.17) log CFU/g in terms of reducing microbial load.

The results for soya the results illustrated there was statistical significance at $p<0.05$ between treatments, the sub (T3) at 15\% the sub of chicken recorded the lowest significance (2.58) log CFU/g in terms of rising microbial load compared to other treatments, especially the sub (T3) at 15\% the sub of Beef that recorded high significance (1.57) log CFU/g in terms of reducing microbial load.

\section{Discussion}

The findings of this investigation revealed distinct variances between all of the therapies. In general, the burgers of various types of meat with oats and soy fillers in various concentrations are finished. Improve the microbial load as well as the sensory score. It is noted that the tenderness was burgers of the chicken and sheep recorded the best significance, 


\section{Coliform}

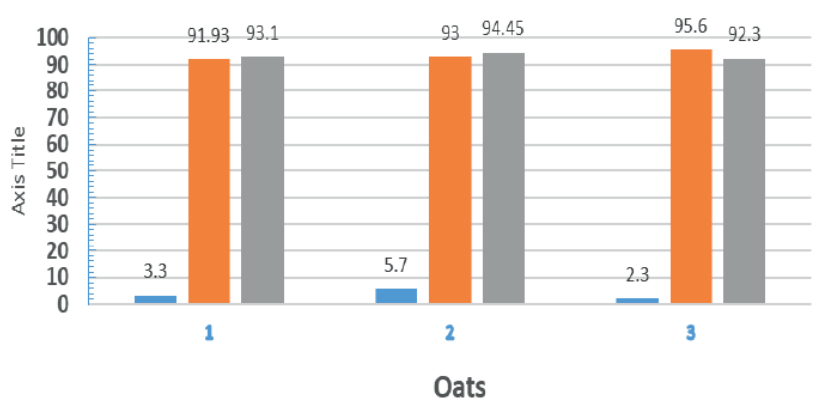

Beef Chicken Sheep

Figure 11. Experimental treatments regarding Coliform with Oats.

\section{Yest\& Mold}

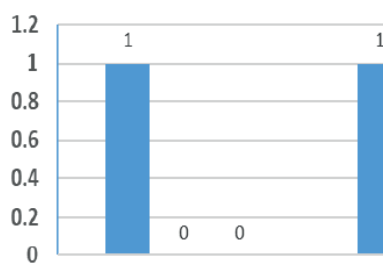

1

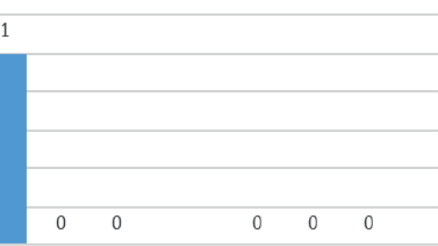

3

Oats

Beef Chicken $\quad$ Sheep

Figure 13. Experimental treatments regarding Yeast \& Mold with Oats.

\section{Total Count Bacteria}

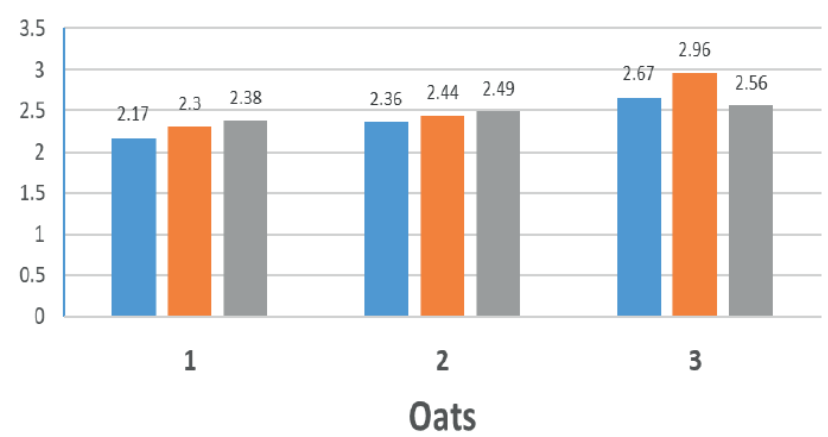

\section{Beef $\quad$ Chicken $\quad$ Sheep}

Figure 15. Experimental treatments regarding Total Count Bacteria with Oats.

for the color of chicken burger recorded the best significance, while the flavor of beef and chicken burgers recorded the best significance. While we note the recorded significance for both the general acceptance and juiciness were burgers of the beef and chicken.

Regarding the microbiology aspect, regarding Yeast \& Mold were burgers chicken and sheep recorded the best significance, regarding Total Count Bacteria where burger of beef recorded the best significance. The desire to replace synthetic food antioxidants with natural ones has sparked study into ve-

\section{Coliform}

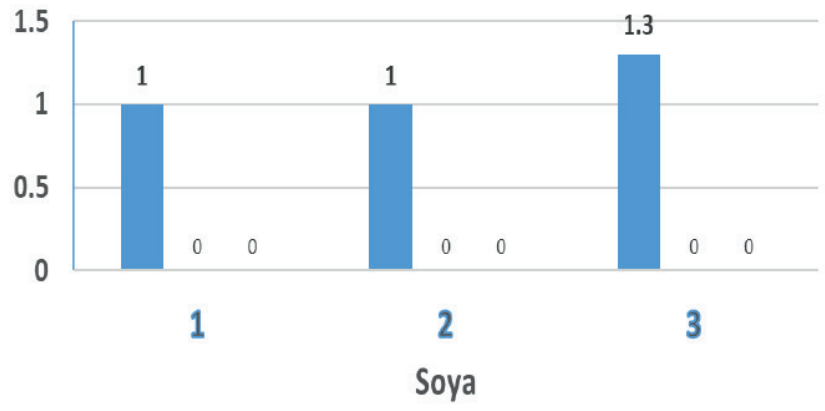

Beef Chicken $\square$ Sheep

Figure 12. Experimental treatments regarding Coliform with Soya.

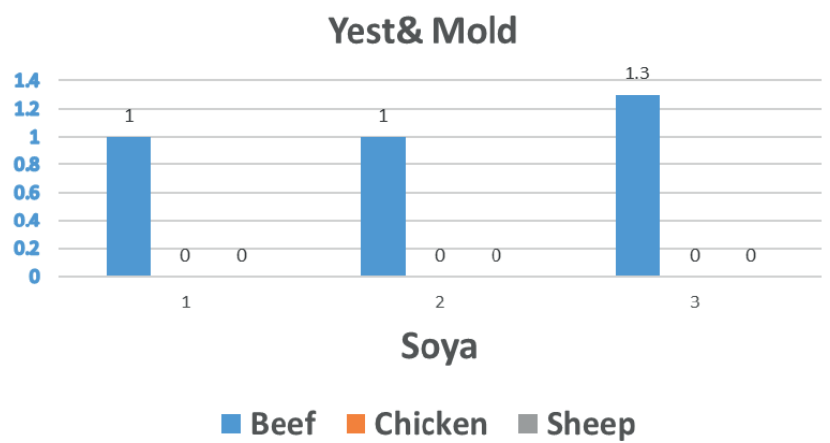

Figure 14. Experimental treatments regarding Yeast \& Mold with Soya.

Total Count Bacteria

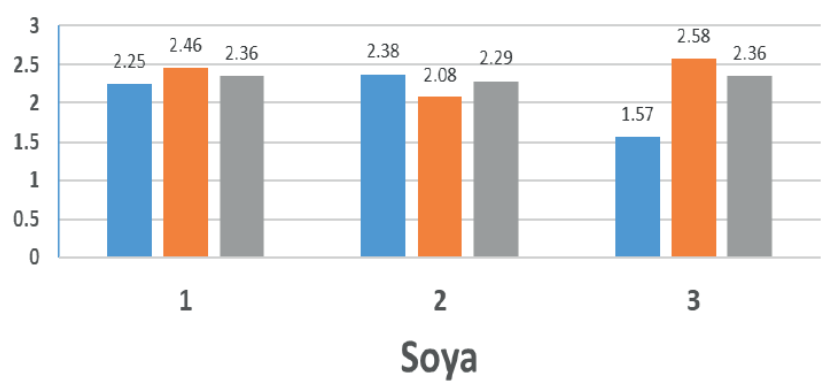

\# Beef Chicken Sheep 
the leading causes of quality loss and the production of potentially harmful secondary chemicals ${ }^{9}$. The proliferation of disease germs can potentially compromise the safety of meat products during the time between production and consumption $^{12}$. As a result of this study, it is clear that the increment of the waste of soybean percentage will lower the percentage of cooking loss, which means that the product that has the highest percentage of soybean, the T2 sample, Due to the soybean propensity to hold fat and water, it creates more juice and weight. Generally, the T3 sample gave the lowest hardness level compared to other samples. Based on the proximate analysis performed, this could be due to a high percentage of fat, as hardness is mostly affected by the fat content of a sample, with a high fat content making the item soft and juicy ${ }^{13}$. The effects of chitosan and/or sulfite addition and the storage time were determined in fresh (color deterioration, lipid oxidation, $\mathrm{pH}$, total viable counts, Escherichia coli and coliforms, Salmonella, appearance and odor) and cooked (appearance, odor, flavor and texture) burgers ${ }^{12}$. Using chitosan to minimize the amount of SO2 needed to increase the shelf life of fresh meat products in retail displays ${ }^{12}$. The growth of E. coli and Salmonella in pork burgers was adequately inhibited by a reduction in SO2 from 450 to 150 mg kgl, ensuring their microbial safety; however, this SO2 reduction was less effective in reducing spoilage bacteria, the usual factor limiting the shelf life of ground meat kept under refrigeration and aerobiosis ${ }^{12}$.

\section{Conclusions}

There is little research on the quality and durability of meat products (burgers) added with fiber. The purpose of this study was to examine the influence of soybean and oat flour as fat replacers and natural antioxidants on the textural quality, microbiological, and sensory acceptability of low-fat meat burgers. Foods with health-promoting features, such as high-fiber and low-fat meat products, are higher. Consumers always have the upper hand when it comes to choosing a food that has been produced using just natural ingredients. Preschoolers, adolescents, and people of all ages should include soya and oats in their diets to increase their nutrient intake, particularly protein, calcium, phosphorus, sodium, potassium, carbohydrate, and iron. These two value-added products are also suitable for vegetarians and persons suffering from cardiovascular disease, obesity, and protein deficiency.

\section{Author Contributions}

All authors designed the experiments, who also drafted the report and approved it for publication.

\section{Conflicts of Interest}

There is no current or disclosed conflict of interest by the authors of this research or in researching this article and its findings.

\section{Bibliographic references}

1. Santhi, D. ; Kalaikannan, A. The Effect of the Addition of Oat Flour in Low-Fat Chicken Nuggets. J. Nutr. Food Sci. 2014. 04.

2. Karwowska, M. ; Dolatowski, Z. J. Physicochemical and Sensory Characteristics of Meat Products with Buckwheat and Oat Extrudates, Starch and Soybean Protein AdditionCharakterystyka Fizykochemiczna I Sensoryczna Wyrobów Mięsnych z Dodatkiem Ekstrudatu Gryki i Owsa, Skrobi Oraz Białka Sojow. Polish J. Nat. Sci. 2008. 23, 219-231.
3. Mattila, P., Pihlava, J. M. ; Hellström, J. Contents of phenolic acids, alkyl- and alkenylresorcinols, and avenanthramides in commercial grain products. J. Agric. Food Chem.2005. 53, 8290-8295.

4. Lin, K. W; Mei, M. Y. Influences of Gums, Soy Protein Isolate, and Heating Temperatures on Reduced-Fat. J. Food Sci.2000. 65, 48-52.

5. Aisha Parveen, Alisha, M. A. ;D. R. P. D. Preparation and standardization of food product by soya chunks and oats as a substitute of meat products and nutraceuticals potential of soybean Aisha. J. Pharmacogn. Phytochem.2018. 7, 1003-1008.

6. García, M. L., Dominguez, R., Galvez, M. D., Casas, C. ; Selgas, M. D. Utilization of cereal and fruit fibres in low fat dry fermented sausages. Meat Sci. 2002 .60, 227-236 .

7. Aminah, A. Prinsip penilaian sensori. Kuala Lumpur. Penerbit Universiti Kebangsaan Malays. 2000.

8. ISO 4831. Microbiology of food and animal feeding stuffs. Horizontal method for the detection and enumeration of coliforms. Most probable number technique, www.iso.org. 2006.

9. Moure, A., Cruz, J. M., Franco, D., Domı खnguez, J. M., Sineiro, J., Domı 囚nguez, H., ... ;Parajó, J. C. Natural antioxidants from residual sources. Food Chem. 2001. 72, 145-171.

10.B. PRASAD, M.D. RASHMI, K. P. Y. ;V. K. M. EFFECT OF CASEIN AND OAT FLOUR ON PHYSICOCHEMICAL AND OXIDATIVE PROCESSES OF COOKED CHICKEN KOFTA. J. Food Process. Preserv. 2011. 35, 359-368.

11. E. M. Desmond, D. J. T. ; D. J. B. The Effects of Tapioca Starch, Oat Fibre and Whey Protein on the Physical and Sensory Properties of Low-fat Beef Burgers. LWT-Food Sci. Technol. 1998 .31, 653-657.

12. Rafael Serrano, S. B. Reducing SO2 in fresh pork burgers by adding chitosan Rafael. Meat Sci.2012. 92, 651-658.

13. Baba, N. ; Bachok, S. Effects of soybean waste on the physicochemical analysis of chicken burgers. J. Tour. Hosp. Culin. Arts 2011.3, 49 